\title{
Los espacios del conocimiento en palacio: de las arcas de libros a las bibliotecas cortesanas en el reino de Castilla
}

\author{
Laura FERNÁNDEZ FERNÁNDEZ \\ Dpto. de Historia del Arte I (medieval) \\ Universidad Complutense de Madrid \\ laurafdez@ghis.ucm.es
}

\section{RESUMEN}

La relación simbólica establecida entre el libro y la monarquía fue una constante a lo largo de la Edad Media, especialmente a lo largo de los siglos del gótico. No obstante junto a este rol simbólico y representativo, el libro se manifestó como un objeto imprescindible para el cumplimiento de otras funciones necesarias en la dinámica palatina. Cada uno de estos roles tendría su particular escenografía, motivando la dispersión del fondo librario por diferentes ámbitos de la corte sin que podamos detectar un lugar específico concebido como biblioteca en términos actuales hasta una cronología tardía, de la misma manera que ocurre en el ámbito religioso.

Palabras claves: Cultura libraria, biblioteca, palacio, reino de Castilla, Alfonso X, Reyes Católicos.

\section{The spaces of knowledge in palace: from the chests of books to court libraries in the Kingdom of Castile}

\begin{abstract}
The symbolic relationship between the book and the crown was a constant throughout the Middle Ages, especially in the Gothic period. Apart from this symbolic and representative role, the book was revealed as an essential object in the dynamics of the royal court, developing specific functions regarding their contents and audience. Each of its functions had their particular scenery, therefore books were necessarily stored in different rooms of the palace, and there were no spaces designed particularly for them. Court libraries will not be common until later periods, just as happened in religious buildings.
\end{abstract}

Key words: Written culture, library, palace, kingdom of Castile, Alfonso X, Reyes Católicos. 
La dimensión simbólica del libro y la cultura escrita como elemento distintivo de los diferentes registros de poder ha sido un tema de estudio constante entre los investigadores de la Edad Media. Es en ese marco contextual en el que debemos destacar la definición del conocimiento como uno de los atributos vinculados a la figura regia durante este periodo, por lo que el monarca tenía la obligación de formarse y cultivar los saberes para hacer un uso correcto y adecuado de los mismos. Es bien conocido el lema del Policratus de Juan de Salisbury, rex illiteratus quasi asinus coronatus, el cual denunciaba los peligros de dejar un reino en manos de un rey ignorante ${ }^{1}$. Bien es cierto, no siempre estas responsabilidades fueron asumidas, o lo fueron con diferentes niveles de intensidad, pero a lo largo de la baja Edad Media la necesidad de perfilar el retrato de un rey letrado se hizo cada vez más patente.

En el marco de la Corona de Castilla, tal y como ha enfatizado Adeline Rucquoi², dicho planteamiento adquirió una especial significación gracias a la rica tradición oriental que se asimiló en la narrativa cortesana a través de los "espejos de príncipes"3. En ese sentido resulta obligado referirse a la figura de Alfonso X quien asumió la sabiduría como el hilo conductor de su acción de gobierno. Basta con acudir a la Partida II, profundamente influida por la tradición de la literatura sapiencial oriental a través de la versión castellana del Sirr al-asrar ${ }^{4}$, donde se afirma que:

"Acucioso debe el rey ser en aprender los saberes, ca por ellos entenderá las cosas de raíz et sabrá mejor obrar en ellas, et otrosí, por saber leer, sabrá mejor guardar sus poridades (secretos) et seer señor dellas, lo que de otra guisa non podrie tan bien facer, ca por la mengua de non saber estas cosas haberie por fuerza de meter otro consigo que lo sopiese, et poderle hie avenir lo que dixo el rey Salomon, que el que mete su poridat en poder de otro fácese su siervo, et quien la sabe guardar es señor de su corazón; lo que conviene mucho al rey. Et aun sin todo esto por la escriptura entenderá mejor la fe, et sabrá mas complidamiente rogar a Dios, et aun por el leer puede él mesmo saber los

1 Remito a dos estudios ya clásicos sobre esta materia, J. DICKINSON, "The mediaeval conception of kingship and some of its limitations, as developed in the Policraticus of John of Salisbury", Speculum: $A$ Journal of Medieval Studies, 1/3 (1926), pp. 308-337; L.K. BORN, "The Perfect Prince: A Study in Thirteenth and Fourteenth Century Ideals", Speculum: A Journal of Medieval Studies, 3/4 (1928), pp. 470-504. JUAN DE SALISBURY, Policraticus, M.Á. LADERO QUESADA (ed.), Madrid, 1984.

2 A. RUCQUOI, "De los reyes que no son taumaturgos: los fundamentos de la realeza en España", Relaciones. Estudios de Historia y Sociedad, XIII, 51 (1992), pp. 55-100; y "El Rey Sabio: cultura y poder en la monarquía castellana medieval”, Repoblación y reconquista (III Curso de Cultura Medieval, 1991), Aguilar de Campoo, 1993, pp. 77-87.

3 Para una aproximación a la problemática de los "Espejos de príncipes" en el reino de Castilla véase: C. ALVAR, A. GÓMEZ MORENO y F. GÓMEZ REDONDO, “Adoctrinamiento de príncipes”, La prosa y el teatro en la Edad Media, Madrid, 1991, pp. 102-112; H.O. BEZARRI, "Las colecciones sapienciales castellanas en el proceso de reafirmación del poder monárquico (siglos XIII y XIV)", Cahiers de Linguistique Hispanique Médiévale, 20 (1995), pp. 35-71; H.O. BEZARRI y A. RUCQUOI, "Los espejos de príncipes en Castilla: entre Oriente y Occidente", Cuadernos de Historia de España, 79 (2005), pp. 7-30; M. HARO CORTÉS, La imagen del poder real a través de los compendios de castigos castellanos del siglo XIII, Londres, 1996; Literatura de castigos en la Edad Media: libros y colecciones de sentencias, Madrid, 2003; y D. NOGALES RINCÓN, "los espejos de príncipes en Castilla (siglos XIII-XV): un modelo literario de la realeza bajomedieval”, Medievalismo, 16 (2006), pp. 9-39.

4 Esta obra se tradujo al castellano como Poridat de Poridades. LL.A. KASTEN, Poridat de Poridades, Madrid, 1957; H.O. BIZARRI, Secreto de los Secretos: Poridat de las Poridades, Valencia, 2010. 
fechos granados que pasaron, de que aprenderá muchos buenos enxiemplos. Et non tan solamiente tovieron por bien los sabios antiguos que los reyes sopiesen leer, mas aun que aprendiesen de todos los saberes para poderse aprovechar dellos"5.

El vínculo establecido entre el monarca y el Saber cómo atributo imprescindible de su dimensión regia se enriqueció con otros parámetros interpretativos, ya que a esa noción simbólica se incorporó la competencia grafo-lectora como un rasgo necesario de la personalidad del soberano. La "escriptura es retenimiento del saber; el que non sabe escrivir es como manco", se afirma en el Libro de los cien capítulos redactado en la década de $1280^{6}$. En dicho texto quedaba ya definido con absoluta claridad el uso de la escritura como herramienta política, "todas las cosas del mundo se guían por la péñola y la espada”, una línea argumental que se mantendría presente durante toda la baja Edad Media castellana, adquiriendo pleno desarrollo en los atributos de los monarcas durante el siglo $\mathrm{XV}^{7}$.

Sirva como ejemplo el retrato del rey Juan II que nos ha transmitido Fernán Pérez de Guzmán, en el que junto a otras virtudes indiscutiblemente unidas a la figura regia, se destaca de forma elogiosa su faceta de rey letrado:

"E porque la condicçion suya fue estraña e maravillosa, es nesçesario de alargar la relación d'ella, ca ansí fue que él era onbre que fablava cuerda e razonablemente, e avía conocimiento de los onbres para entender cuál fablava mejor e más atentado e más graçioso. Plazíale oír los onbres avisados e graçiosos, e nota mucho lo que d'ellos oía. Sabía fablar e entender latín, leía muy bien, plaziánle mucho libros y estorias, oía muy de grado los dizires rimados e conoçia los viçios d'ellos, avía grant placer en ori palabras alegres e bien apuntadas, e aun él mesmo las sabía bien dizir. Usava mucho la caça e el monte, e entendía bien toda la arte d'ello. Sabía dell arte de la música, cantava e tañía bien, e aun en el justar e juegos de cañas se avía bien"».

Gracias a la crónica del mismo rey sabemos que su madre, la reina doña Catalina, designó a Gómez Carrillo de Cuenca para que adoctrinara al príncipe, formación que sería completada posteriormente a cargo de fray Lope de Barrientos, y el propio don Juan elegiría a "un bohemio llamado Gerónimo, que le mostrase á escrebir" al

5 Partida II, Título V, Ley 16. ALFONSO X, Las Siete Partidas, Madrid, 1807, T. II, p. 37. “Cómo el rey debe seer acucioso en aprender leer, et de los saberes lo que pudiere".

6 M. HARO CORTÉS, (ed.), Libro de los cien capítulos (Dichos de sabios en palabras breves e complidas), Frankfurt, 1998; y "Libro de los cien capítulos", Los compendios de castigos del siglo XIII, pp. 66-71; M. ZAPATA Y TORRES, "Breves notas sobre el Libro de los cien capitulos como base de las Flores de filosofia", Smith College Studies in Modern Languages, 10 (1929), pp. 43-54; H.O. BIZZARRI, "Deslindes históricoliterarios en torno a Flores de filosofia y Libro de los cien capitulos", Incipit, 15 (1995), pp. 45-63.

7 Sobre este particular véase E. RUIZ GARCÍA, "El poder de la escritura y la escritura del poder", J. M. NIETO SORIA, Orígenes de la monarquía hispánica: propaganda y legitimación (ca. 1400-1520), Madrid, 1999, pp. 275-314.

8 R.B. TATE (ed.), Generaciones y Semblanzas, Londres, 1965, pp. 38-39. 
príncipe don Enrique ${ }^{9}$. Lo mismo podemos decir de doña Isabel, quien cuidaría con esmero la educación de sus hijos, tal y como puso de manifiesto Antonio de la Torre ${ }^{10}$.

El libro, por lo tanto, se instaló en la corte como un atributo de poder y autoridad regia, parte esencial de la compleja maquinaria de la simbólica cortesana, contribuyendo a la suntuosidad del escenario palatino. No obstante, junto a este rol simbólico, el libro se manifestó como una herramienta imprescindible para el cumplimiento de otras funciones evidentes y necesarias en la dinámica palatina: instrumento para la labor pedagógica y docente, pieza clave para el desarrollo de la faceta piadosa y devocional, herramienta propagandística y legisladora, así como mecanismo de evasión y divertimento. Cada uno de estos roles tendría su particular escenografía, motivando la dispersión del fondo librario por diferentes ámbitos de la corte sin que podamos detectar un lugar específico concebido como biblioteca en términos actuales hasta una cronología tardía, de la misma manera que ocurre en el ámbito religioso ${ }^{11}$.

El espacio del libro en palacio es un espacio no unitario, sino caleidoscópico, que se adapta a las necesidades cortesanas y evoluciona al igual que lo hace la relación entre el lector y el libro en el desarrollo de la baja Edad Media ${ }^{12}$. Por otra parte, los libros no permanecían inmóviles en un determinado lugar, sino que viajaban con sus posesores ${ }^{13}$, se trasladaban junto con las pertenencias de la corte, y eran utilizados como piezas de pago y agasajo en múltiples contextos ${ }^{14}$.

9 Capítulo XLVIII. "De como Pedro de Velasco estando en la villa de Haro, fue poner el cerco á la villa de San Vicente en Navarra, é la tomó por la fuerza de armas", FERNÁN PÉREZ DE GUZMÁN, Crónica del señor rey don Juan, segundo de este nombre en Castilla y León, Valencia, 1779, p. 288.

10 A. DE LA TORRE, "Maestros de los hijos de los reyes católicos", Hispania, 63 (1956), pp. 256-266.

11 M.D. CAMPOS SÁNCHEZ-BORDONA y M. DOLORES TEIJEIRA, "Aproximación a una tipología arquitectónica: Las librerías Catedralicias de Castilla y León (España)", Medievalista, 6 (2009) on-line. L. FERNÁNDEZ, "El libro en la catedral durante la Edad Media: espacio y función", Lope de Barrientos. Seminario de Cultura, 1 (2008), pp. 123-146.

12 La bibliografía sobre este aspecto ha experimentado una atención notable en las últimas décadas y son muy numerosas las referencias. Sirvan como punto de partida la publicación sobre Historia de la lectura editada por Guglielmo Cavallo y Chartier, así como el artículo de Paul Saeger sobre la lectura silenciosa. G. CAVALLO y R. CHARTIER, Histoire de la lectura dans le monde occidental, Paris, 1997; P. SAEGER, "Silent Reading: Its Impact on Late Medieval Script and Society", Viator, 13 (1982), pp. 367-414. Para el caso español es interesante destacar el recopilatorio de trabajos de I. BECEIRO, Libros, lectores y bibliotecas en la España medieval, Murcia, 2007. Otros textos de interés en el desarrollo de la lectura y la relación entre el lector y el libro durante la baja Edad Media, J. CERQUIGLINI-TOULET, La Couleur de la mélancolie, La fréquentation des livres au XIVe siècle, Paris, 1993; J. BRANTLEY, Reading in the Wilderness: private devotion and public performance in late medieval England, Chicago, 2008; D.H. GREEN, Women Readers in the Middle Ages, Cambridge, 2011.

13 Resulta inevitable en este contexto mencionar la conocida cantiga 209 en la que el rey enfermo en Vitoria solicita que le sea entregado su libro sobre los cantares de la Virgen, "Libro dela" para ser utilizado como objeto taumatúrgico que le sane de la enfermedad que padece. "Como el Rey Don Affonso de Castela adoeçeu en Bitoria e ouv'hua door tan grande que coidaron que morresse ende, e poseron-lle de suso o livro das Cantigas de Santa Maria, e foi guarido". Transcripción de Mettmann utilizada en la edición facsímil de F. El Codice de Florencia, de las Cantigas de Santa Maria, Madrid, 1991, p. 112.

14 En el testamento y otros documentos de la reina Isabel encontramos múltiples referencias a esta doble circunstancia, el disponer de los libros como bien material que pueda ser utilizado para subsanar una deuda o el gesto de gratitud o agasajo expresado a través de la entrega de libros. Véase E. RUIZ GARCÍA, Los libros de Isabel la Católica: arqueología de un patrimonio escrito, Madrid, 2004. En este sentido, nuevamente relacionado con los manuscritos de las Cantigas, resulta apropiado citar la entrega del llamado Códice de Florencia a don Andrés Cabrera por parte de la reina. L. FERNÁNDEZ, "Historia Florentina del Códice de 


\section{Los saberes en la corte alfonsí}

Una de las figuras que encarna con mayor claridad el paradigma del rey letrado es sin lugar a dudas Alfonso X. Un soberano plenamente consciente del papel que le había sido asignado en el devenir del desarrollo del reino castellano, y que asumió la sabiduría como su atributo distintivo más destacado. Sin embargo lo que le otorga aún mayor interés es el hecho de que no sólo moldeó su figura con las directrices del rey sabio, sino que construyó una corte letrada que pudiera servir de receptora e interlocutora de sus dictados ${ }^{15}$.

Si retomamos la cita alfonsí de la Partida II, vemos como se especificaba que:

"non tan solamiente tovieron por bien los sabios antiguos que los reyes sopiesen leer, mas aun que aprendiesen de todos los saberes para poderse aprovechar dellos".

Y según nos relata don Juan Manuel en su Crónica Abreviada, en la corte de Alfonso X,

"auia muchos maestros de las ciencias e de los saberes a los quales el fazia mucho bien (e) por leuar adelante el saber e por noblesçer sus rregnos, ... ca moraua en algunos logares vn año e dos e mas, e avn segunt dizen los que viuian a la su merced, que fablauan con el los que querían e quando [querían] e quando el queria, e ansi auia espacio de estudiar en lo que el queria fazer p[or] si mismo e avn para veer e esterminar las cosas de los saberes que el mandaua ordenar a los maestros e a los sabios que traya para esto en su corte" ${ }^{16}$.

Y entre los diferentes saberes que se cultivaron en el ámbito cortesano alfonsí, el desarrollo de los trabajos de naturaleza científica adquirió un protagonismo notable, destacando de forma significativa el estudio de la "ciencia de las estrellas" 17 . El taller científico vinculado a la corte de don Alfonso llevó a cabo un trabajo de máxima relevancia en el desarrollo del pensamiento científico hispano y europeo durante la baja Edad Media, haciendo uso de la rica tradición oriental que fue revisada, reelaborada y utilizada como base de obras de nueva factura como las

las Cantigas de Santa María, Ms. B.R. 20. De la Biblioteca Palatina a la Nazionale Centrale”, Reales Sitios, 164, (2005), 18-29.

15 Resulta siempre interesante remitir a los trabajos de Fernando Gómez Redondo para una correcta definición del concepto de corte letrada en el ámbito alfonsí. Véase F. GÓMEZ REDONDO, Historia de la prosa medieval castellana, I La creación del discurso prosístico: el entramado cortesano, Madrid, 1998, especialmente el capítulo "La corte letrada de Alfonso X (1256-1284)"; y "Modelos políticos y conducta del rey en la literatura del siglo XIII", Cahiers de linguistique hispanique médiévale, 23 (2000), pp. 285-304.

16 DON JUAN MANUEL, Crónica Abreviada, (prólogo), J.M. BLECUA (ed.), Don Juan Manuel. Obras completas, II. Madrid, 1983, p. 505.

17 Sobre los trabajos de carácter científico realizados en la corte del rey Sabio existe una nutrida bibliografía. Sirvan como referencia de conjunto: M. COMES, Y J. SAMSÓ, (coord.) De Astronomia Alphonsi Regis: actas del Simposio sobre Astronomía Alfonsí celebrado en Berkeley (agosto 1985) y otros trabajos sobre el mismo tema, Barcelona, 1987; y Ochava espera y Astrofisica. Textos y estudios sobre las fuentes árabes de la astronomía de Alfonso X, Barcelona, 1990; L. FERNÁNDEZ, Arte y Ciencia en el scriptorium de Alfonso X el Sabio, Sevilla-Puerto de Santa María, 2013. 
conocidas Tablas Alfonsíes. Un grupo de científicos que se trasladaría con la corte, desarrollando su trabajo principalmente allá donde morase el rey. Prueba de ello nos proporciona el Libro del saber de astrología, uno de los compendios científicos realizados durante este periodo, de mayor interés y complejidad. El manuscrito, conservado en la Biblioteca Histórica de la Universidad Complutense de Madrid ${ }^{18}$, nos revela una valiosa información en este sentido ya que está datado en el año 1278 en la ciudad de Burgos, coincidiendo con el itinerario del monarca ${ }^{19}$.

Sí es posible establecer el carácter itinerante de los colaboradores científicos del rey, cuanto más el de los juristas, oficiales necesariamente cercanos a la figura regia, tal y como es especificado en el Espéculo:

[El emperador y el rey] "e an consigo sienpre sabidores de fuero e de derecho en su corte porque todo omne deve sospechar que sus iuyzios son derechos e conplidos" ${ }^{20}$.

Lo mismo podríamos argumentar de los miembros del taller historiográfico, así como de los trovadores, quienes igualmente tenían que estar en contacto directo con el monarca. Si retomamos una vez más el prólogo del Espéculo, de nuevo queda implícito el hecho de que en la corte se dispusiera de un espacio en el que se realizaran las copias necesarias para desempeñar las funciones específicas asignadas a cada uno de estos escritos:

"E por esto damos ende libro en cada villa seellado con nuestro seello de plomo e toviemos este escripto en nuestra corte, de que son sacados todos los otros que diemos por las villas" ${ }^{21}$.

Por lo tanto, tal y como se trasluce del texto de don Juan Manuel, es de suponer que la corte castellana sería capaz de disponer de un espacio, o espacios, adecuado para la ejecución de los productos del escritorio regio a pesar de la itinerancia de la misma.

18 Ms. 156 BH. Sobre este manuscrito véase M. RICO Y SINOBAS, Libros del Saber de Astronomia, del Rey D. Alfonso X de Castilla, Tomos I - V, Madrid, 1863- 67. A. CARDENAS, “A Medieval Spanish Collectanea of Astronomical Instruments: An Integrated Compilation”, Journal of the Rocky Mountain Medieval and Renaissance Association, 1 (1980), pp. 21-28; y "A new title for the alfonsine omnibus on astronomical instruments", La Coronica, VII, 2, (1980), pp. 172-178; y "A Survey of Scholarship on the Scientific Treatises of Alfonso X, el Sabio", La Coronica, 11.2 (1982-1983), pp. 231-47; y "Hacia una edición crítica del Libro del Saber de Astrologia de Alfonso X: estudio codicologico actual de la obra regia, (mutilaciones, fechas y motivos)", Homenaje a Pedro Sainz Rodriguez, II, Madrid, 1986, pp. 111-120; y A study and Edition of the Royal scriptorium Manuscript of El Libro del Saber de Astrología by Alfonso X el Sabio, Ph.D. diss., University of Wisconsin, 1974; L. FERNÁNDEZ, op. cit., 2013, pp. 213-279.

19 M. GONZÁLEZ JIMÉNEZ y M.A. CARMONA RUIZ, Documentación e Itinerario de Alfonso X el Sabio, Sevilla, 2012.

20 G. MARTÍNEZ DÍEZ, (ed.), Leyes de Alfonso X, I: Espéculo, Ávila, 1985. V, XIV, 11. Todas las referencias a este texto se harán a partir de la citada edición.

21 Espéculo, Prólogo, I. 


\section{Espacios y funciones del libro en palacio}

La labor pedagógica y docente desempeñada en el ámbito cortesano tuvo un especial protagonismo en el desarrollo de las actividades palatinas, especialmente enfocada al adoctrinamiento de los príncipes y otros miembros de la nobleza. De nuevo la Partida II, nos proporciona una pormenorizada explicación de que es la corte, y por qué las bondades y las buenas enseñanzas se llaman cortesía:

"Y por ello fue en España siempre acostumbrado por los hombres honrados enviar a sus hijos a criar a las cortes de los reyes, porque aprendiesen a ser corteses, y enseñados y quitos (libres) de villanía y de todo yerro, y se acostumbrasen bien, así en dicho como en hecho, porque fuesen buenos" 22 .
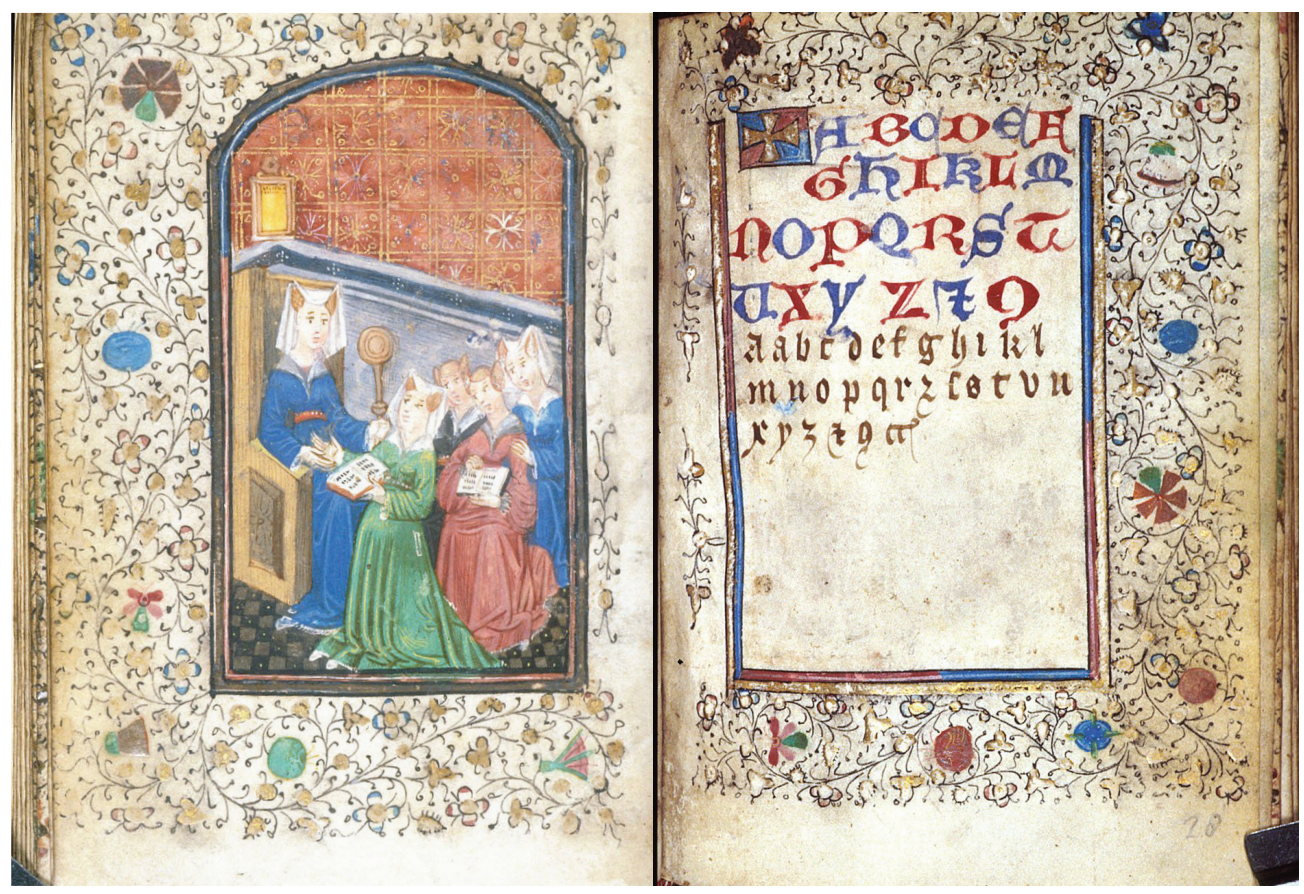

Fig. 1. Libro de horas, Holanda, Ms. Harley 3828, British Library, ff. 27v-28r, ca. 1445.

Por lo tanto en la corte se daban cita los jóvenes de la nobleza que eran enviados a palacio para recibir la educación adecuada en la definición de su estatus, por lo que era necesario establecer espacios destinados a la enseñanza que pudieran dar cobertura a esta labor docente, así como que en la corte se dispusiera de los libros apropiados para llevar a cabo dicha labor.

22 Partida II, Título IX, Ley 27. 
Son múltiples las imágenes de espacios docentes que nos han sido transmitidas a través de los repertorios bajomedievales, especialmente en soporte manuscrito. En estas escenas que transcurren en dependencias de palacio habilitadas para el magisterio, el profesor alecciona a sus discípulos que atentamente le escuchan con sus libros en la mano. Entre las numerosas imágenes en las que se representan a maestros con sus discípulos quisiera mencionar un interesante libro de horas de factura holandesa que incorpora entre las oraciones un alfabeto así como algunos textos para lectores principiantes. Junto al alfabeto, en el folio enfrentado, asistimos a una clase de lectura para damas de la corte dirigida por una maestra, quien se dispone a aleccionar a una de ellas, probablemente por no haber desempeñado adecuadamente su tarea ${ }^{23}$ (fig. 1).

Como vemos con este ejemplo, los libros no eran utilizados únicamente por su propio contenido, sino como canal de aprendizaje de otras disciplinas: lectura, gramática, escritura, así como la formación intelectual y espiritual. Contamos con el valioso inventario de los libros destinados a la formación de los hijos de los reyes católicos ${ }^{24}$, entre los que se encontraban obras de gramática, autores clásicos, textos jurídicos, de naturaleza histórica, así como varios ejemplares de regimientos de príncipes, y un mapamundi. También encontramos libros de música, un tratado de cetrería, y material para ejercitar su escritura. Entre el elenco de objetos escriturarios que figuran en dicho inventario llaman especialmente la atención varias entradas en las que se recogen diversos libros para dibujar, probablemente realizados con tablillas de madera, o de pizarra ${ }^{25}$ que pudieran ser utilizadas en múltiples ocasiones, en lugar de usar el pergamino o el papel como soporte:

"dos libros de debuxar, uno negro de nueve tablas con su çerradura y su cabo, y otro blanco de otras nueve tablas con su çerradura y su cabo de latón".

Uno de los espacios preferentes para el desarrollo de la lectura fueron sin duda las cámaras privadas o retretes. Este lugar recogido era especialmente apropiado para llevar a cabo lecturas piadosas, y de hecho los libros de rezo se guardaban en estos espacios, tal y como nos han hecho saber los inventarios de la época. Las fuentes iconográficas también son muy explícitas para ilustrar esta ubicación libraria ya que son múltiples los ejemplos que contamos con representaciones de la Virgen y figuras de Santas retratadas a modo de damas de la época realizando sus lecturas piadosas en el marco de su cámara, y junto a ellas los lugares en los que dichos libros se de-

23 K. RUDY, “An Illustrated Mid-Fifteenth-Century Primer for a Flemish Girl: British Library, Harley MS 3828", Journal of the Warburg and Courtauld Institutes, 69 (2006), pp. 51-93.

24 E. RUIZ GARCÍA, op. cit., 2004.

25 Este material está notablemente documentado para el uso de los conocidos como "libros de memoria", material habitual en los usos cortesanos, de los que se conocen múltiples ejemplos a lo largo del siglo XVI. De hecho la propia reina Isabel disponía de "cinco libricos para escribir memorias", tal y como atestigua el inventario de 1505. A. DE LA TORRE Y DEL CERRO, Testamentaría de Isabel la Católica, Barcelona, 1974, p. 114. Sobre este formato y su uso en la corte española véase F. BOUZA, Palabra e imagen en la Corte. Cultura oral y visual de la nobleza en el Siglo de Oro, Madrid, 2003, esp. pp. 48-56; J.L. GONZALO SÁNCHEZ-MOLERO, Regia Bibliotheca. El libro en la corte española de Carlos V, Mérida, 2004, III, esp. pp. 166-170; A. CASTILLO GOMEZ, Entre la pluma y la pared. Una historia social de la escritura en los siglos de oro, Madrid, 2006, pp. 61-69. 
positaban. Entre las múltiples imágenes que podrían traerse a colación para ilustrar este particular me remito a la Anunciación de posible origen alemán que custodia el Metropolitan Museum of New York en el que la Virgen, leyendo en la intimidad de su cámara es sorprendida por el anuncio del ángel. Junto al atril, en la parte superior, se pueden ver varios estantes con libros depositados ${ }^{26}$ (fig. 2).

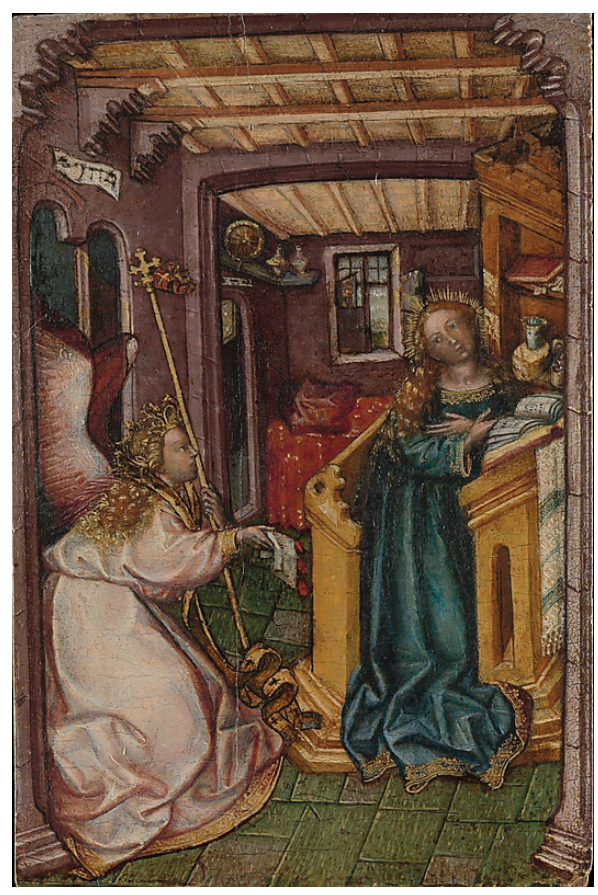

Fig. 2. Anunciación, Metropolitan Museum of New York, alemán? ca.1455.

Bien es cierto en estos espacios de carácter privado también se llevarían a cabo otro tipo de lecturas de variada naturaleza. En este sentido contamos con diversos documentos de destacado interés que nos proporcionan información sobre los libros que entre 1477 y 1483 solicitó la reina doña Isabel al tesorero encargado del tesoro depositado en el alcázar en Segovia ${ }^{27}$. Entre ellos contamos con diversos libros de temática espiritual, varios regimientos de príncipes, libros de contenido jurídico, pero también hay espacio para el divertimento y el ocio ya que están registrados dos libros de "cançiones apuntadas", y el Libro del ajedrez, dados y tablas de Alfonso $\mathrm{X}^{28}$.

26 M. AINSWORTH, "Recent Acquisitions, A Selection: 2004-2005", Metropolitan Museum of Art Bulletin, 63 (2005), p. 15.

27 E. RUIZ GARCÍA, op. cit., 2004.

28 Para la fortuna del Libro de los juegos véase L. FERNÁNDEZ, "El Libro del axedrez, dados e tablas, Ms. T-I-6, Real Biblioteca del Monasterio de El Escorial. Estudio codicológico", VV.AA, El Libro del axedrez, dados e tablas de Alfonso X el Sabio, Valencia, 2010, pp. 69 - 116. 
No debemos olvidar que entre las actividades que se consideraban adecuadas para el ocio cortesano, la música y el juego del ajedrez ocuparon un lugar preferente. Bien es cierto, la lectura también desempeñó un papel protagonista. En la Partida II, Título XXI, Ley 20, se expresa la noble costumbre de los antiguos de leer durante la comida "estorias delos grandes fechos de armas que los otros fizieran", costumbre que se mantendría durante siglos como parte del ocio y el aprendizaje de los jóvenes en palacio, tal y como ha quedado recogido en la obra de Alonso de Cartagena ${ }^{29}$.

El ambiente sofisticado y refinado de la corte en la que el libro ocupaba un papel protagonista, necesariamente tuvo que verse reflejado en las residencias de los linajes castellanos, produciéndose un "mimetismo bibliófilo" 30 que provocaría la creación de ricas colecciones librarias nobiliarias, tendencia que se desarrolló especialmente en el último cuarto del siglo $\mathrm{XV}^{31}$. Eco de esta influencia cortesana debemos interpretar la conocida frase de Juan de Lucena en su carta a Fernán Álvarez Zapata:

"La muy clara ninfa Carmenta letras latinas nos dio: perdidas en nuestra Castilla, esta diva serena las anda buscando [...] ¿No vedes cuantos comienzan a aprehender mirando su realeza? Lo que los reyes facen, bueno o malo, todos ensayamos de los facer. Si es bueno, por aplacer á nos mesmos; y si malo, por aplacer á ellos. Jugaba el rey (Enrique IV), éramos todos tahures; estudia la Reina, somos agora todos estudiantes" ${ }^{2}$.

29 J.N.H. LAWRANCE, Un tratado de Alonso de Cartagena sobre la educación y los estudios literarios, Barcelona, 1979.

30 Utilizo la afortunada expresión de A. CANELLAS, "Bibliotecas medievales hispanas", Cuadernos de historia Jerónimo Zurita, 31-32 (1978), pp. 259-268.

31 Sobre las principales bibliotecas nobiliarias castellanas existen numerosos títulos; bien es cierto los aspectos que se han tratado de forma más desarrollada han sido aquellos vinculadas con las temáticas recogidas en las colecciones librarias, no tanto sobre las cuestiones directamente vinculadas con la biblioteca como espacio específico. A. PAZ Y MELIÁ, "La biblioteca del conde de Haro”, RABM, 1 (1897), pp. 18-24, 60-66, 156-63, 255-62, 452-62; M. SCHIFF, La bibliotheque du Marquis de Santillane, París, 1905; F.J. SÁNCHEZ CANTÓN, La biblioteca del marqués de Cenete iniciada por el Cardenal Mendoza (1470-1523), Madrid, 1942; M. PENNA, "La Biblioteca de los Mendoza del Infantado en el siglo XV" Exposición de la Biblioteca de los Mendoza del Infantado en el siglo XV con motivo de la celebración del V Centenario de la muerte de don Ínigo López de Mendoza, Marqués de Santillana, Madrid, 1958, pp. 13-26; M.A. LADERO QUESADA y M.C. QUINTANILLA RASO, "Bibliotecas de la Alta Nobleza Castellana en el siglo XV", Livre et lecture en Espagne et en France sous l'Ancien Régime, Madrid, 1981, pp. 47-62; I. BECEIRO PITA y A. FRANCO SILVA, "Cultura nobiliaria y bibliotecas. Cinco ejemplos, de las postrimerías del siglo XIV a mediados del XVI", Historia. Instituciones. Documentos, 12 (1986), 1-74; I. BECEIRO, "La Biblioteca del conde de Benavente a mediados del siglo XV y su relación con las mentalidades y usos nobiliarios de la época", En la España medieval, 2 (1982), pp. 135-146; P. CÁTEDRA, "Sobre la biblioteca de los Mendoza del Infantado en el siglo XV: la Ilíada y Pier Candido Decembrio" Hispanic Review, 51 (1983), pp. 23-28; F. UTRILLA UTRILLA, "Una biblioteca nobiliar aragonesa de mediados del siglo XV: inventario de libros de Alfonso de Liñán (1468), señor de Cetina (Zaragoza)", Aragón en la Edad Media, II, Zaragoza, 1987, pp. 177-198; F. SALGADO OLMEDA, "Humanismo y coleccionismo librario en el siglo XV. Las bibliotecas renacentistas de Santillana, Infantado y el Cardenal Mendoza", Wad-al-Hayara: Revista de estudios de Guadalajara, 22 (1995), pp. 123-135; M. IAN, "Private book-collecting in Spain from St. Isidore (570-636) to the Marqués de Santillana (1398-1458)", Donaire, 12 (1999), pp. 21-32.

32 JUAN DE LUCENA, "Epístola exhortatoria a las letras”, A. PAZ Y MELIÁ, (ed.), Opúsculos literarios de los siglos XIV y XVI, Madrid, 1892, p. 216. 


\section{El mobiliario para los libros}

Para poder adaptar y transformar las dependencias cortesanas que no disponían de una arquitectura específica para el desarrollo de estas actividades, entraba en juego una pieza fundamental e imprescindible para la transformación del espacio interior: el mobiliario. Un mobiliario versátil, que sirviera como elemento contenedor de los volúmenes, pero también para articular el espacio de trabajo de los profesionales de la péñola.

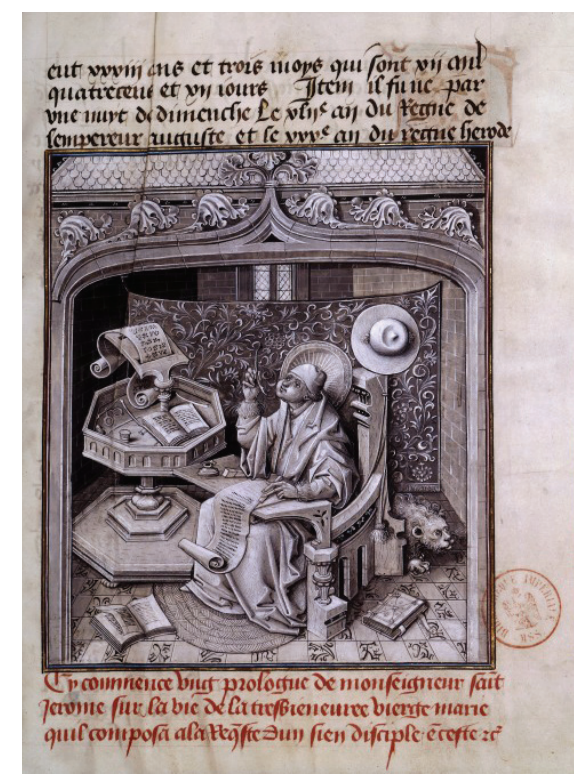

Fig. 3. San Jerónimo escribiendo, Jean Miélot, Miracles de Notre Dame, Ms. Français 9198, Bibliothèque nationale de France, f. 2r, 1456.

Las arcas de libros resultaban imprescindibles en este sentido, elementos móviles que permitían tanto el almacenamiento como el traslado de los volúmenes en caso de que fuera necesario, una necesidad que debido a la itinerancia de la corte castellana debió ser una constante. Arcas, arquillas, cofres, de diferentes tamaños y materiales, están documentados en los inventarios de libros. Y junto a estas arcas también encontramos múltiples referencias al armarium destinado a contener los volúmenes, una pieza de larga tradición presente sobre todo en ámbitos eclesiásticos ${ }^{33}$, pero que necesariamente tuvo que ser adoptada por los profesionales del saber ubicados en el ámbito cortesano. Estos armaria y estantes de madera o de albañilería, tal y como

33 Entre las representaciones de armaria más reconocibles se encuentran sin lugar a dudas la del armarium de los mosaicos de Gala Placidia, en Rávena, s. V, y el que nos muestra la biblioteca de la que dispone Ezra en su representación en el Codex Amiatinus, Ms. 6, Biblioteca Medicea Laurenziana, s. VIII. 
podemos apreciar en múltiples representaciones, se verían complementados por mesas de trabajo que también cumplirían la función de ser receptáculos de libros, incorporando en muchos casos piezas giratorias que permitirían la consulta de varios ejemplares $^{34}$ (figs. 3 y 4 ).

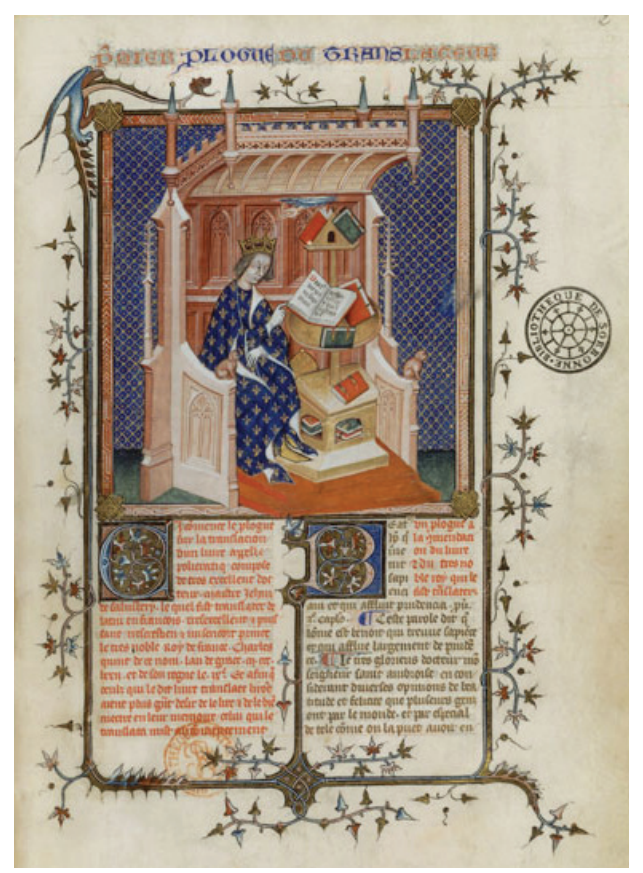

Fig. 4. Un rey consultando varios libros. Policraticus, Joan de Salisbury, Ms. Français 24287, Bibliothèque nationale de France, f. 2r, 1372.

\section{Los libros en la capilla palatina}

Además de los diferentes espacios domésticos repartidos en el espacio de la residencia regia, debemos mencionar la presencia de los libros litúrgicos destinados a la capilla palatina, así como a los oratorios personales de los monarcas. Tal y como ha puesto de manifiesto David Nogales ${ }^{35}$ muchos de los objetos de los que se hacía uso en ceremonias litúrgicas relevantes eran tomados en préstamo del tesoro real.

34 Sobre el mobiliario específico de las bibliotecas a lo largo de la Edad Media remito al estudio fundamental de B.H. STREETER, The chained library, Cambridge, 1931 (Reed. 2011), así como a J.F. GENEST, «Le mobilier des bibliothéques», Vocabulaire du livre et de l'écriture au Moyen Age, Turnhout, 1989, pp. 136-154. Para el caso hispano los trabajos de Isabel Beceiro siguen siendo la referencia ineludible: I. BECEIRO PITA, "Los espacios del libro en Castilla y Aragón a fines del Medievo", Litterae: Cuadernos de cultura escrita, 1 (2001), pp. 119-136 (Reed. en Libros, lectores y bibliotecas en la España Medieval, Murcia, 2007).

35 D. NOGALES, La representación religiosa de la realeza castellano-leonesa: la Capilla Real (12521504), Tesis Doctoral, UCM, Madrid, 2009, p. 361. 
Sin embargo en ocasiones se cita expresamente el ornamento específico de la capilla, así como los libros de las capillas personales de diferentes monarcas. Estos libros, además del uso activo que los monarcas hicieran de ellos, solían cumplir con una función de carácter piadoso al ser donados en las testamentarías para formar parte de las colecciones librarías depositadas en las capillas funerarias de fundación regia. De esta manera los libros que habían guiado la oración de los monarcas en vida, seguían siendo utilizados para velar por la salvación de sus almas.

Entre los numerosos ejemplos en los que se cita la donación de los ornamentos de las capillas personales de los monarcas para que pasaran a formar parte de sus capillas funerarias ${ }^{36}$, es obligado destacar el conocido caso de Alfonso X por la presencia protagonista que adquieren los libros en la manda testamentaria. Además de mencionar libros y objetos especialmente significativos pertenecientes al tesoro de la corte, son expresamente citados los libros de su capilla personal ${ }^{37}$, aquellos que a petición del rey debían quedar depositados en el templo donde fuere enterrado y que finalmente quedaron en la Capilla Real sevillana, de los que Teresa Laguna ha identificado un epistolario que pudo formar parte de dicha colección ${ }^{38}$.

En el caso de los Reyes Católicos los documentos relacionados con sus testamentarías también nos proporcionan datos relativos a los libros específicos de la capilla de palacio aunque no de manera directa. Doña Isabel dejó establecido en su testamento que sus bienes fueran dispuestos para pagar deudas, especificando que los ornamentos litúrgicos de su capilla personal se enviaran a Granada ${ }^{39}$, aunque en ese documento nada se decía sobre los libros. Siguiendo la pauta establecida por su esposa, Fernando, tras la muerte de la reina, decidió enviar a la Capilla Real un número nutrido de obras artísticas entre las que se encontraban algunos manuscritos que formaban parte de los fondos librarios de la Corona, y aunque en principio se debían haber enviado solo los libros litúrgicos tanto de la capilla de la reina como

36 D. NOGALES, op. cit., 2009, p. 363.

37 "otrossi mandamos que todas las vestimentas de nuestra capella con todos los otros libros que los den a la iglesia de Sancta María de Seuilla o a la iglesia de Murcia, si el nuestro cuerpo fuere y enterrado, sacado aquellas vestimentas que mandamos dar señaladamente a la iglesia de Sancta María de Seuilla [...]". Codicilo de testamento de Alfonso X (Sevilla, 10-I-1284), M. GONZÁLEZ JIMENEZ, Diplomatario andaluz de Alfonso X, Sevilla, 1991, nº 521, p. 560.

38 T. LAGUNA, "Epistolario. Castilla Primer Tercio Siglo XIII", Metropolis Totius Hispaniae. 750 Aniversario de la Incorporación de Sevilla a la Corona Castellana, Sevilla, 1998, pp. 230-231; y "Epistolario", Maravillas de la España Medieval: Tesoro Sagrado y Monarquía, Valladolid, 2001, p. 251; y "Si el Nuestro cuerpo fuere enterrado en Sevilla, Alfonso X y la Capilla de los Reyes”, Alfonso X, el Sabio, Murcia, pp. 116129, esp. 128.

39 "E para cunplir e pagar las debdas e cargos susodichos e las otras mandas e cosas en este mi testamento contenidas, mando que mis testamentarios tomen luego e distribuyan todas las cosas que yo tengo en los alcáçeres de la çibdad de Segovia e todas las ropas e joyas e otras cosas de mi cámara e de mi persona e qualesquier otros bienes que yo tengo donde podieren ser avidos, salvo los ornamentos de mi capilla, sin las cosas de oro e plata, que quiero e mando que sean llevadas e dadas a la Iglesia de la çibdad de Granada; pero suplico al Rey, mi señor, se quiera servir de todas las dichas joyas e cosas o de las que a su Señoría más agradaren porque veyéndolas pueda aver más contina memoria del singular amor que a su Señoría sienpre tove e aún porque sienpre se acuerde que ha de morir e que lo espero en el otro siglo e con esta memoria pueda más sancta e justamente bivir". [Testamento de Isabel I (12-X-1504, Medina del Campo). AGS, Patronato Real, leg. 30-2, fol. 8r. A. DE LA TORRE Y DEL CERRO, op. cit. Barcelona, 1974, ítem 40. 
de la del rey, como demuestra el inventario conservado las materias y objetos seleccionados fueron variopintos, y procedentes de distintos fondo ${ }^{40}$. Lamentablemente no se conserva documentación sobre el traslado y la recepción de los libros, y el testimonio más antiguo que avala la presencia de los ejemplares en la fundación regia es el del embajador veneciano Andrea Navagiero, quien en el año 1526 declaraba haber visto los libros en una dependencia sobre la sacristía ${ }^{41}$ y no sería hasta el año 1536 cuando se llevara a cabo un inventario en el que quedaron recogidos los ejemplares allí depositados ${ }^{42}$.

\section{Formación de las colecciones librarias en palacio}

Entre los libros que circularon en la corte es necesario distinguir entre dos conceptos que afectaron directamente a la formación de las colecciones reales librarias. Por una parte debemos considerar aquellos libros que fueron destinados a formar parte del patrimonio librario de la Corona, incluso algunos que fueron concebidos como un elemento consustancial a la misma y fueron transmitidos en heredad a sus sucesores como parte del tesoro del reino, y por otra aquellos libros que pertenecieron a los monarcas u otros miembros de la corte a título personal. Nos interesa fundamentalmente el primer núcleo ya que dicho fondo es el origen de la biblioteca real, entendida ésta durante la baja Edad Media como el fondo patrimonial librario de la Corona.

Son varios los ejemplos que conservamos en relación a la transmisión de ciertos libros como elementos de dicho valor patrimonial regio. Recurro de nuevo a don Alfonso ya que su codicilo es muy rico en información. En él se hace una relación de diferentes libros en poder del monarca, destinados a aquel que "con derecho por nos heredare el nuestro señorio mayor de Castilla é León" 43 , por lo que es de suponer que Sancho reclamara dicho legado para sí, ya que estos libros permanecieron vinculados a las arcas de palacio.

En el prólogo de la Crónica de Alfonso XI queda plenamente establecido que los libros formaban parte consustancial del tesoro regio:

"Esta es la muy alta et muy noble et mucho honrada et muy nombrada et muy virtuosa et muy sancta Coronica del muy noble Señor Rey Don Alfonso de Castiella et de Leon [...] Et mandola trasladar el muy noble rey Señor rey Don Enrique, su fijo de este noble Señor rey Don Alfonso, de quien fabla esta Coronica, para el su muy

40 Entre los libros del tesoro del Alcázar que fueron destinados a Granada se encontraban dos de los manuscritos de Alfonso X, el Libro de los juegos, (Ms. T-I-6, RBME), y el Libro de las formas et las ymágenes, (Ms. h-I-16, RBME). Gracias a la petición expresa de Felipe II en 1591 para su devolución a los fondos de la Corona, viajaron a los anaqueles de la Real Biblioteca del Monasterio de El Escorial, en la que se encuentran actualmente custodiados. Para la fortuna de estos manuscritos véase L. FERNÁNDEZ, op. cit., 2010; y op. cit., 2013, p. 287.

41 E. RUIZ GARCÍA, op. cit., 2004, p. 123.

42 A. GALlEGO BURÍN, "Nuevos datos sobre la Capilla Real de Granada", Boletín de la Sociedad Española de Excursiones, 57 (1953), pp. 67-116.

43 M. GONZÁLEZ JIMÉNEZ (ed.), op. cit., Sevilla, 1991. 
honrado et muy real et muy largo et muy franco et muy noble tesoro. El muy noble Señor Rey Don Enrique de Castiella et de Leon mandó a Joan Nuñez de Villazan Alguacil mayor de su la su casa, que la ficiese trasladar en pargaminos" ${ }^{44}$.

Dicho fondo, o al menos una parte significativa del mismo, debió permanecer en Sevilla hasta mediados del siglo XIV. Prueba de ello es la copia que se lleva a cabo en 1341 en la ciudad hispalense del Libro del saber de astrología ${ }^{45}$, uno de los textos que estuvo vinculado al fondo patrimonial de la Casa del rey. En qué momento los libros abandonaron Sevilla no podemos determinarlo con seguridad ${ }^{46}$, lo que si conocemos es su destino final, el alcázar de Segovia. En el año 1390 en el Ordenamiento de Segovia el monarca Juan I planteaba la necesidad de establecer la Audiencia en dicha ciudad de forma estable, rompiendo de esta manera con el carácter itinerante congénito de las instituciones administrativas castellanas. Tal vez este sea un punto a tener en cuenta en el planteamiento del alcázar de Segovia como centro gestor de los bienes de la Corona, y por lo tanto del tesoro regio. El primer dato que nos sitúa el emplazamiento del tesoro en el alcázar segoviano es el proporcionado por el testamento de Enrique III datado el 24 de diciembre de $1406^{47}$, en el que se cita expresamente el tesoro dispuesto en la torre del homenaje a cargo de Alfonso García de Cuéllar, su contador mayor. No obstante los alcázares de Madrid y de Valladolid siguieron desempeñando el papel de depósitos de parte del tesoro regio en tiempos de Juan $\mathrm{II}^{48}$, siendo durante el reinado de Enrique IV cuando el alcázar segoviano adquiriese pleno protagonismo ${ }^{49}$. Al cargo de estas piezas se encontraba un funcionario real encargado de gestionar y administrar correctamente dichos bienes que podían ser prestados a petición del monarca, un cargo que a mediados del siglo XV fue ocupado por Juan de Tordesillas, camarero del rey Enrique IV, cargo que pasaría a su hermano, Rodrigo de Tordesillas. A él le correspondió realizar el inventario del tesoro en el año 1503 a petición de la reina doña Isabel, un documento de gran importancia ya que nos ha transmitido cuantiosa información del fondo librario de la Corona a principios del siglo XVI.

44 F. CERDÁ Y RICO, Crónica de D. Alfonso el onceno de este nombre, de los reyes que reynaron en Castilla y en León, Madrid, 1787, p. 3.

45 L. FERNÁNDEZ, op. cit., 2013, pp. 252-256.

46 En el año 1369 Pedro I se vio obligado a trasladar el tesoro al alcázar de Carmona, por lo que es probable que los libros que formaban parte de él también viajaran. Crónicas de los Reyes de Castilla, C. ROSELL (ed.), Madrid, 1953. (3 vols), Crónica del rey don Pedro, t. 66, p. 585.

47 Crónicas de los Reyes de Castilla, op. cit, Testamento del rey Enrique III, t. 68, pp. 266-278.

48 Testamento de Juan II (Valladolid, 8-VII-1454), Memorias de Enrique IV de Castilla, Madrid, $1913, \mathrm{t}$. II, $\mathrm{n}^{\mathrm{o}}$ XLVI, p. 120.

49 M.A. LADERO QUESADA y M. CANTERA MONTENEGRO, "El tesoro de Enrique IV en el alcázar de Segovia. 1465-1475", Historia. Instituciones. Documentos, 31 (2004), pp. 307-351. M.A. LADERO QUESADA, "Capilla joyas y armas, tapices y libros de Enrique IV de Castilla", Acta historica et archaeologica mediaevalia, 26 (2005), pp. 851-874; P. MARTÍNEZ-BURGOS GARCÍA, "Enrique IV, mecenazgo y utopía en el siglo XV castellano", Actas del IX Congreso Español de Historia del Arte, León, 1994, vol. I, pp. $315-$ 320 . 


\section{Hacia la definición de la biblioteca como espacio habitacional}

La información que nos transmite la documentación conservada en relación a la consulta y uso de los libros en la corte en este momento, sigue proporcionándonos un mosaico de espacios del libro vinculados a sus usos y funciones, sin atisbarse la necesidad de definir un espacio comunitario para la consulta de los volúmenes. Es ya en la segunda mitad del siglo XV cuando surgen algunas referencias relativas a ejemplos concretos vinculados a casas nobles, que dejan entrever la aparición de las primeras bibliotecas en residencias nobiliarias concebidas como espacios habitacionales específicos. Sirvan como ejemplos más significativos la librería que el primer marqués de Santillana mandó construir en Guadalajara en su codicilo de 1455, o Alfonso de Velasco, quien cita en su testamento de 1476 la librería donde tenía varias obras ${ }^{50}$.

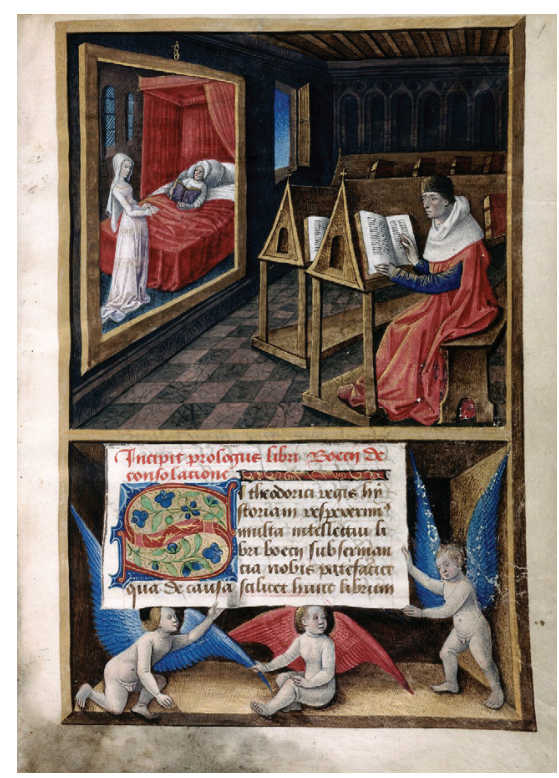

Fig. 5. Boecio en su biblioteca, Le Livre de Boece de Consolacion, Ms. Harley 4335, British Library, f. 1r, 1477.

Estos espacios dispondrían también de mobiliario adecuado para la consulta de los libros, tal y como disponían las bibliotecas eclesiásticas y las universitarias ${ }^{51}$ (fig. 5).

50 Véase A. ANTELO IGLESIAS, "Las bibliotecas del Otoño medieval. Con especial referencia a las de Castilla en el siglo XV", Espacio, Tiempo y Forma, S. III, Historia Medieval, 4 (1991), pp. 285-352; I. BECEIRO PITA, "Libros, nobles y letrados. El caso de Castilla”, op. cit., Murcia, 2007.

51 Sirvan a modo de bibliografía general sobre la historia de las bibliotecas catedralicias y universitarias como espacios habitacionales: J. WILLIS CLARK, The care of books. An essay on the development of libraries and their fitting from the earliest time to the end of Eighteenth century, Cambridge, 1901; A. MASSON, Le Décor des bibliothèques du Moyen Age à la Revolution, Ginebra-París, 1972; A. VERNET (dir.) Histoire del 
Una de las viñetas que acompaña el texto de Boecio en un manuscrito de la British Library, Ms. Harley 4335, nos muestra al autor en su biblioteca, una estancia llena de bancos corridos con pupitres en atril en los que están depositados varios libros para ser consultados, una imagen que sin duda se estaría inspirando en las bibliotecas que en esos años comenzaban a proliferar en los espacios palatinos.

Sin embargo, el concepto de biblioteca de uso y consulta libraría, no cristalizaría en el ámbito cortesano hispano hasta el siglo XVI.

\section{El rey como promotor de espacios librarios fuera de la corte}

Resulta interesante que las acciones de los monarcas destinadas a la creación de bibliotecas o centros de estudio se produjeran fuera de la corte. Alfonso IX de León creó el Estudio General de Salamanca, institución que recibió el apoyo de la Corona de forma sistemática, y es bien conocida la fundación de los "Estudios generales de latín e arábigo" llevada a cabo por Alfonso X en la ciudad de Sevilla ${ }^{52}$. Estos focos culturales debían contar con bibliotecas que sirvieran a sus propósitos, ya que según manifiestan las Partidas ${ }^{53}$,

"bien y lealmente debían los maestros mostrar sus saberes a los escolares leyéndoles los libros y haciéndoselos entender lo mejor que ellos pudieren".

Unos meses antes de la fundación del Estudio General en Sevilla el 8 de diciembre de 1254 , el rey reclamaba al arzobispo y al cabildo de la ciudad unas mezquitas, pues pensaba dedicarlas,

"para morada de los físicos que vinieron de allende, e para tenerlos más cerca, (del alcázar es de suponer), e que fagan la su enseñanza a los que les hemos mandado que nos lo enseñen por el su gran saber, ca por eso los hemos ende traido" ${ }^{54}$.

En el caso de los Reyes Católicos, los esfuerzos para crear un centro difusor de la cultura y del ideario político isabelino se canalizaron en la creación de la biblioteca de San Juan de los Reyes ${ }^{55}$, a cuya librería la reina destinó cuantiosas sumas, así como su implicación directa en el estudio salmantino.

bibliothèques françaises, vol. I, Les bibliothèques médiévales du VIe siècle à 1530, París, 1989. A. MUÑOZ COSME, Los espacios del saber. Historia de la arquitectura de las bibliotecas, Madrid, 2004.

52 Memorial Histórico Español, Madrid, 1851, t. I, pp. 54-56.

53 Las disposiciones relativas a la fundación de Estudios Generales, así como todos los aspectos relacionados con su actividad, se encuentran en la Partida II, XXXI.

54 J. VARGAS PONCE, Elogio del Rey Don Alonso el Sabio, Madrid, 1782, pp. 70-71.

55 A. ABAD PEREZ, "La biblioteca franciscana de Toledo (1284-1808)", Anales Toledanos, XX-XXI (1984-1985), pp.11-35; J.M. AZCÁRATE, "Sentido y significación de la arquitectura hispano-flamenca en la corte de Isabel la Católica", Boletín del Seminario de Estudios de Arte y Arqueología, 37 (1971), pp. 201-223; E. RUIZ GARCÍA, op. cit., 2004, p. 202, nota 372. 


\section{La imprenta en las bibliotecas cortesanas de finales de la Edad Media}

Para finalizar con este sucinto periplo por los espacios del libro en la corte castellana, quisiera reflexionar brevemente sobre el impacto que supuso la imprenta en el incremento de las colecciones librarias de la segunda mitad del siglo XV, cuestión que necesariamente desembocaría en la ampliación de los espacios destinados al libro, tanto fuera como dentro de palacio. Una circunstancia que caminaría de la mano con el cambio de mentalidad y la forma de enfrentarse a la producción escrita por parte del medio letrado e intelectual del momento.

A pesar de que hoy día se acepta de forma generalizada que la primera obra impresa en España de la que se tiene constancia es el Sinodal de Aguilafuente, llevado a cabo por Juan Párix de Heidelberg en 1472 en Segovia ${ }^{56}$, los libros impresos en distintos focos europeos tuvieron que llegar con anterioridad a Castilla. Contamos en ese sentido con un dato valioso, el inventario de los libros de la cámara de don Álvaro de Zúñiga realizado en 1468 en el que se menciona un libro de Séneca "escrito de molde" ${ }^{57}$, por lo que el conocimiento, uso y adquisición de este nuevo producto librario estuvo activo antes del inicio de la actividad impresora en el reino castellano.

La imprenta supuso una revolución definitoria en el volumen de la producción libraria y su difusión, produciéndose de forma paralela un fenómeno de bibliofilia social que no sólo recomendaría, sino que obligaría a la tenencia de libros, libros que en muchas ocasiones no serían leídos por sus posesores, sino que serían utilizados únicamente como signo de distinción social. No es extraño que Sebastian Brant pusiera en la proa de su nave de los necios, editada en 1494, a un personaje, el bibliomaníaco, cuya imagen abre el libro con las siguientes palabras:

"el primer danzante soy en el baile de los necios, pues sin provecho muchos libros tengo, que ni leo ni entiendo" 58 (fig. 6).

No obstante el libro siguió desempeñando un papel fundamental en el ámbito cortesano, y la estrecha relación de la dimensión regia con la cultura escrita siguió pro-

56 Juan Párix. Primer impresor en España, Segovia, 2004 (catálogo de la exposición); F. DE LOS REYES, "Segovia y los orígenes de la imprenta española", Revista general de información y documentación, 15/1 (2005), pp. 123-148.

57 M.A. LADERO Y M. QUINTANILLA, op. cit., 1981.

58 "De los libros inútiles. El que yo esté sentado delante en el barco, tiene en verdad una especial intención; no se ha hecho sin motivo. Confío en mi biblioteca. De libros tengo gran tesoro, aunque en ellos entiendo muy pocas palabras, y los tengo en tal veneración, que hasta los defiendo de las moscas. Donde se habla de ciencias, digo yo: en casa las tengo yo muy bien. Me contento con ver muchos libros ante mí. El rey Ptolomeo se procuró todos los libros del mundo y consideró esto un gran tesoro; más no encontró la doctrina verdadera ni pudo instruirse con ella. Yo tengo asimismo muchos liros, pero leo poquísimo en ellos. ¿A qué iba a querer romperme la cabeza y agobiarme completamente bajo el peso del saber? Quien mucho estudia se vuelve fantasioso. Yo me tengo, no obstante, por un señor y pago a uno que aprende para mí. Cierto que poseo una mente tosca, pero cuando estoy con sabios puedo decir ita "sí". Contento estoy de pertenecer a la orden del alemán, pues se muy poco latín; sé que vinum significa "vino", gucklus "cuco", stultus "necio", y que yo me llamo domine doctor. Tengo las orejas ocultas, pues de otro modo, se vería pronto la acémila del molinero". SEBASTIAN BRANT, La nave de los necios, A. REGALES SERNA (ed.), Madrid, 2011, pp. 95-96. 


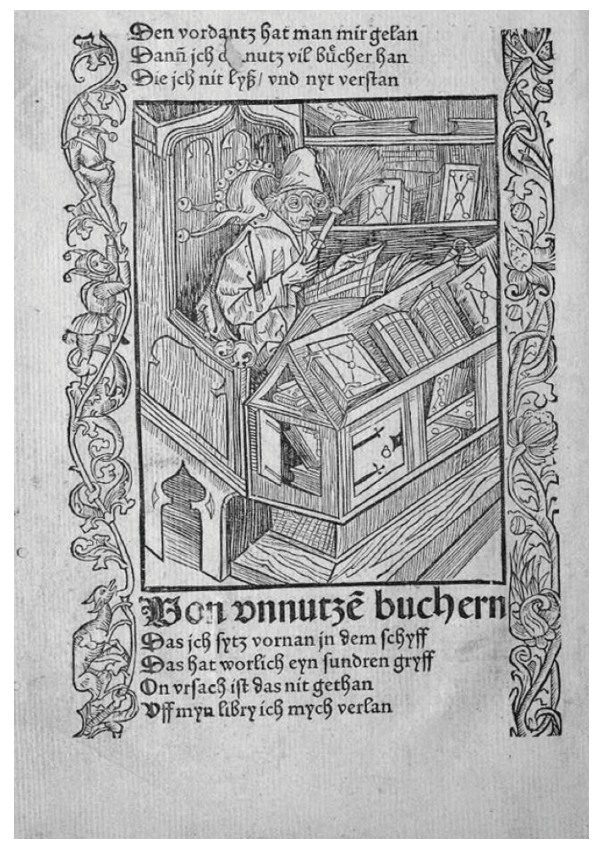

Fig. 6. El Bibliomaníaco, Sebastian Brant, La nave de los necios, 1494.

duciendo excelentes frutos dentro y fuera de palacio $^{59}$, a pesar de que la necia bibliomanía se instaló en una sociedad que gustaba de cultivar las apariencias, algo que por otra parte a día de hoy no nos resulta muy lejano.

59 En este sentido es imprescindible mencionar la creación de la Real Biblioteca del Monasterio de El Escorial en tiempos de Felipe II. G. DE ANDRÉS MARTÍNEZ, La Real Biblioteca de El Escorial, Madrid, 1970 . 